\title{
Lip repositioning with a myotomy of the elevator muscles for the management of a gummy smile
}

\section{Repozycja wargi przez przecięcie przyczepów mięśni dźwigacza w leczeniu uśmiechu dziąsłowego}

\author{
Asmaa Mohammad Alammar ${ }^{1, D}$, Omar Ahmad Heshmeh ${ }^{2, D}$ \\ ${ }^{1}$ Faculty of Dentistry, Damascus University, Syria \\ ${ }^{2}$ Department of Oral and Maxillofacial Surgery, Faculty of Dentistry, Damascus University, Syria \\ A - research concept and design; $\mathrm{B}$ - collection and/or assembly of data; $\mathrm{C}$ - data analysis and interpretation; \\ $\mathrm{D}$ - writing the article; $\mathrm{E}$ - critical revision of the article; $\mathrm{F}$ - final approval of the article
}

\begin{abstract}
Address for correspondence
Asmaa Alammar
\end{abstract}

E-mail: asma.alammar90@gmail.com

Funding sources

None declared

Conflict of interest

None declared

Received on April 16, 2018

Reviewed on May 19, 2018

Accepted on June 15, 2018

D0I

$10.17219 / \mathrm{dmp} / 92317$

Copyright

○ 2018 by Wroclaw Medical University

and Polish Dental Society

This is an article distributed under the terms of the

Creative Commons Attribution Non-Commercial License

(http://creativecommons.org/licenses/by-nc-nd/4.0/)

\begin{abstract}
Background. Excessive gingival display $\geq 4 \mathrm{~mm}$ is commonly referred to as a "gummy smile", which is caused by several different etiologies and can be corrected using various techniques. Therefore, the etiology of a gummy smile dictates the most appropriate treatment approach.
\end{abstract}

Objectives. The aim of this study was to evaluate the surgical lip repositioning technique (a full-thickness flap with a myotomy of the elevator muscles) in the management of a gummy smile in the range of 4-6 mm, caused by soft tissue disorders (short upper lip, hyperactive lip elevator muscles).

Material and methods. A prospective study was conducted between April 2016 and May 2017. Fourteen adult patients, aged 18-38 years, with a gummy smile of $4-6 \mathrm{~mm}$, caused by soft tissue disorders were included in the study. All patients were treated by the surgical lip repositioning technique (a full-thickness flap with a myotomy of the elevator muscles) in the Department of Oral and Maxillofacial Surgery at Damascus University, Syria. The amount of gingival display in a full smile and complications after surgery were evaluated in the current study.

Results. The results were as follows: the mean amount of gingival display in a full smile was $6.36 \mathrm{~mm}$ preoperatively, after 1 month postoperatively $-0.91 \mathrm{~mm}$, after 3 months $-2.27 \mathrm{~mm}$, after 6 months $-2.45 \mathrm{~mm}$. The post-surgery complications were as follows: the infection did not appear in any patient, flap dehiscence appeared in 2 patients (14.2\%), numbness appeared in 9 patients (64.2\%). Pain recurrences varied between mild pain in 5 patients (35.7\%) and moderate pain in 3 patients (21.4\%).

Conclusions. The proposed surgical lip repositioning technique showed effectiveness in reducing the amount of gingival display in a full smile through postoperative follow-up periods. All the postoperative complications are temporary and fade within a short period after the surgical procedure, making lip repositioning a safe surgical technique.

Key words: gingival display, gummy smile, lip repositioning, myotomy of elevator muscles

Słowa kluczowe: ekspozycja dziąseł, uśmiech dziąsłowy, repozycja wargi, przecięcie przyczepów mięśni dźwigacza 


\section{Introduction}

An attractive, esthetic smile is one of the basic demands for most people all over the world. ${ }^{1}$ The ideal smile is a result of the harmonious interaction between 3 important components: the lip, teeth and gingiva. Normal gingival display in a full smile is about 1-3 $\mathrm{mm}$ between the lower border of the upper lip and the marginal gingiva of anterior superior incisors. ${ }^{2} \mathrm{On}$ the other hand, abnormal gingival display reaching $4 \mathrm{~mm}$ or more is commonly referred to as a "gummy smile", and it is classified as an unattractive smile by dentists and people. ${ }^{2,3}$ The percentage of men and women with a gummy smile amounts to approx. $7 \%$ and $14 \%$, respectively. ${ }^{4}$ There are several different etiologies that can cause a gummy smile, such as vertical maxillary excess (skeletal factors), passive delayed eruption or compensatory eruption of maxillary teeth, especially in class 2 malocclusion (dentoalveolar factors), ${ }^{1,5,6}$ short upper lip or hyperactive lip elevator muscles, which are known as soft tissue factors, ${ }^{7,8}$ in addition to genetic factors, which can also play a role in causing a gummy smile. ${ }^{9}$ According to the abovementioned etiologies, a gummy smile can be treated by using several techniques, such as orthodontic surgery, gingivectomy or surgical crown lengthening, botox injection, myotomy of the lip elevator muscles, and surgical lip repositioning. Sometimes, a gummy smile can be caused by multiple etiologies and requires a multidimensional approach. ${ }^{1,3}$ That is why the underlying etiology of a gummy smile dictates the most appropriate treatment approach. ${ }^{10,11}$

Lip repositioning is an innovative surgical technique for correcting a gummy smile. It was first reported in 1973 by Rubinstein and Kostianovsky, who performed it by removing a strip of the labial mucosa, involving the upper lip frenum, apical to the mucogingival junction. ${ }^{\text {acc.12 }}$ Since then, the procedure has undergone many different alterations. In 1979, as a modification of the original lip repositioning, the midline maxillary labial frenum was not recommended to be excised to facilitate maintaining the position of the labial midline. ${ }^{\text {acc. } 1}$ In 1983, Miskinyar performed lip repositioning with a myotomy of the upper lip elevator muscles, which was again endorsed by Litton and Fournier by using the same technique in cases with short upper lip. acc.6,13 $^{\text {at }}$ In 2010, Ishida et al. reported cases treated with a myotomy of the lip elevator muscles and a frenectomy. ${ }^{14}$ Furthermore, Ellenbogen and Swara supported the method of inserting a spacer in 2 schemes: nasal cartilage or prosthesis between the stumps. ${ }^{15}$ This last method was to prevent the reunion of the muscles and re-elevation of the lip. Rees and Latrenta described a camouflage procedure through the columella, by performing a subperiosteal dissection of the upper lip elevator muscles. ${ }^{\text {acc.14 }}$ According to the medical literature on surgical lip repositioning, there are some contraindications in the following cases $^{4,5}$ :

- patients with inadequately attached gingiva $(<3 \mathrm{~mm})$ in the maxillary anterior sextant, which can create difficulties in the flap design, stabilization and suturing;

- patients with a gummy smile caused by skeletal factors, such as vertical maxillary excess (gingival display in a smile $>6 \mathrm{~mm}$ ) (such patients should be treated with orthognathic surgery);

- uncontrolled systemic disease patients and smokers.

Reports in the literature have shown some postoperative complications, such as discomfort, bruising and swelling of the upper lip. A less frequent complication may be the formation of mucocele due to severed minor salivary glands in the upper lip, which resolves on its own and relapses postoperatively. Other rare complications that have been reported in the literature are paresthesia and transient paralysis. ${ }^{4,12}$ However, it appears that medical literature lacks systematic clinical studies on the different techniques of surgical lip repositioning. There are no previous studies concerning our modified technique, which is a full-thickness flap (V-shaped in the upper lip frenum) with a myotomy of the elevator muscles for lip repositioning in the management of a gummy smile.

Our research aimed at evaluating the modified lip repositioning technique (a full-thickness flap with a myotomy of the elevator muscles) in the management of a gummy smile ranging from 4 to $6 \mathrm{~mm}$, caused by soft tissue disorders (short upper lip, hyperactive lip elevator muscles), as well as postoperative complications.

\section{Material and methods}

The study sample included 14 adult patients aged 18-38 years, diagnosed with a gummy smile ranging between 4 and $6 \mathrm{~mm}$, caused by soft tissue disorders (short upper lip, hyperactive lip elevator muscles), referred to the Department of Oral and Maxillofacial Surgery at the Faculty of Dentistry, Damascus University, Syria, between April 2016 and May 2017. These patients were treated using a surgical lip repositioning technique (a full-thickness flap with a myotomy of the lip elevator muscles).

Inclusion criteria were as follows: 18-38 years of age, safety of gingival health and good oral health, good general health or a controlled systemic disease, and a gummy smile ranging from 4 to $6 \mathrm{~mm}$, caused only by short upper lip and hyperactive lip elevator muscles (lip mobility $>8 \mathrm{~mm}$ ).

Exclusion criteria comprised: smoking, pregnancy or lactation, insufficient amount of attached gingiva $(<3 \mathrm{~mm})$, vertical maxillary excess (gingival display in a smile $>6 \mathrm{~mm}$ ), and a systemic disease considered a contraindication for a surgical procedure under local anesthesia.

Informed consent was signed by each of the subjects after the objectives, design, risks, and potential benefits of our study were explained. 


\section{Preoperative procedure}

Photographic images of full smiles were taken preoperatively to compare with postoperative images (Fig. 1A). In the full-smile position, gingival display was measured by a gingival probe, which was placed parallel to the longitudinal axis of the teeth between the left and right second upper premolars; gingival display was measured from the inferior border of the upper lip vermillion to the gingival margin of the anterior maxillary teeth (Fig. 1B). Extraoral and intraoral antisepsis was applied with $2.0 \%$ chlorhexidine solution and $0.12 \%$ chlorhexidine rinse for $1 \mathrm{~min}$.
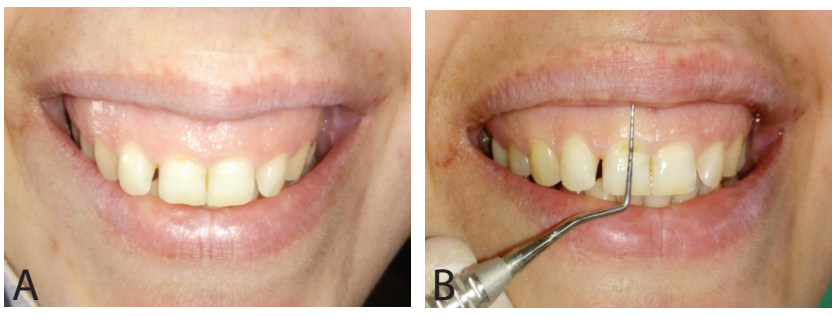

Fig. 1. Preoperative smile (A); measurement of gingival display from the inferior border of the upper lip to the free gingival margin of the anterior maxillary teeth in a full smile (B)

\section{Surgical technique}

Firstly, anesthesia was administered by an infraorbital injection on both sides (2\% lidocaine with 1:80,000 epinephrine). Then, a sterile surgical marking pen was used to mark the incision outline on the dried tissues (Fig. 2A,2B). Following this, a full-thickness incision was made nearly $1 \mathrm{~mm}$ coronal to the mucogingival junction from the mesial line angle of the right first molar to the mesial line angle of the left first molar, which was $\mathrm{V}$-shaped in the upper lip frenum area. Such a modification is implemented to help preserve the position of the labial midline. The $2^{\text {nd }}$ full-thickness incision was made in the labial mucosa, parallel to the $1^{\text {st }}$ incision and 10-12 mm apical to it. The 2 incisions were connected at each first molar on both sides, creating an elliptical outline. The epithelium was removed within the outline of the incisions. Then, the attachments of the perioral muscles were dissected from the bone (Fig. 2C-2E). It has to be noted that the amount of tissue excision should be double the amount of gingival display that needs to be reduced, with a maximum of $10-12 \mathrm{~mm}$ of tissue. In the present study, all patients had a gummy smile in the range of 4-6 $\mathrm{mm}$, so the width of the tissue strip removed was $8-10 \mathrm{~mm}$. The 2 incision lines were approximated by suturing the muscle layers with Vicryl ${ }^{\circledR}$ 4/0 (GarnTec GmbH, Neidenfels, Germany) (Fig. 2F). Then, the mucosa layer was sutured with interrupted stabilization sutures (silk 3/0) (GarnTec GmbH) at the midline and other locations along the borders of the incision to ensure proper
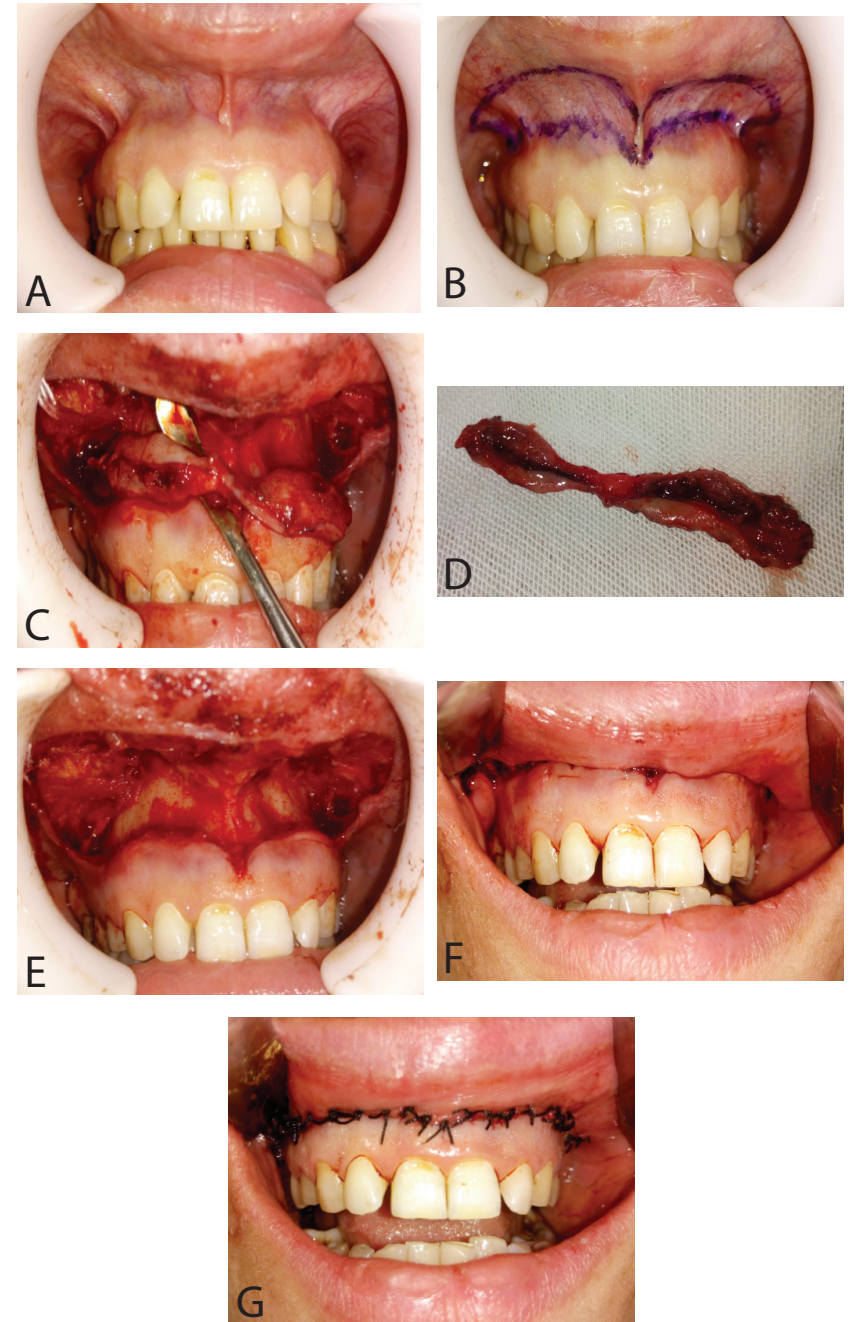

Fig. 2. Preoperative area (A); the incision outline is made with a sterile surgical marking pen (B); the epithelial and muscle layers are removed (C); the removed strip of the epithelial and muscle layers (D); a full-thickness flap exposes the flap underlying the connective tissue (E); the muscle layer sutures (F); interrupted mucosal sutures $(G)$

alignment of the lip midline of the teeth. Afterwards, additional interrupted sutures were used to approximate both flap ends (Fig. 2G).

All patients were given nonsteroidal anti-inflammatory drugs (Flam-K ${ }^{\circledR}$; Neopharma, Damascus, Syria; 50 mg, 3 times/day), oral antibiotics (Augmentin ${ }^{\circledR}$; SmithKline Beecham, New York, USA; 1g, 2 times/day) and 0.12\% chlorhexidine rinse for 1 week postoperatively. Postoperative instruction for all patients included the application of ice packs over the upper lip for several hours, minimizing lip movement when smiling or talking during the first 2 weeks, and avoiding any mechanical trauma to the surgery sites by limiting food intake to only soft foods during the first week. Pain was managed with analgesics. Finally, the suture was removed 2 weeks later (Fig. 3A) and the suture outline was treated, leaving a scar that was not visible when the patient smiled, as it was hidden in the upper lip mucosa (Fig. 3B). Most of the patients reported only tension in the upper lip with a minimum of discomfort and ecchymosis postoperatively. 

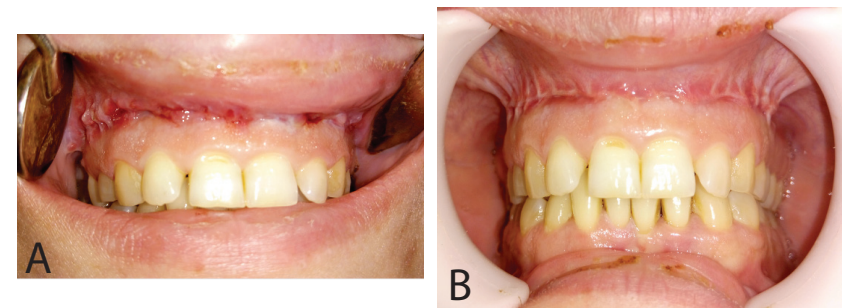

Fig. 3. Sutures removed after 2 weeks (A); healing site after 6 months (B)

\section{Follow-up after surgery}

All patients were followed up at 1, 3 and 6 months postoperatively. The parameter that was assessed during a full active smile (Fig. 4) was the amount of gingival display from the inferior border of the upper lip vermillion to the gingival margin of the anterior maxillary teeth, from the right second premolar to the left second one, measured with a gingival probe placed parallel to the longitudinal axis over the mid-buccal region of the anterior maxillary teeth. All measurements were registered to the nearest millimeter. If part of the clinical crown was covered by the lip (postoperatively), the gingival display level was set at zero point. The follow-up included the recording of postoperative complications, such as infection, dehiscence, numbness, and other complications, as well as questions to the patients to determine if the complications had occurred or not. The postoperative pain was assessed using the visual analog scale (VAS) during follow-up periods. Furthermore, the whole surgical procedure and clinical measurements, taken postopeatively at 1-, 3- and 6-month follow-ups, were set by 1 surgeon to avoid partiality and the variance of results.
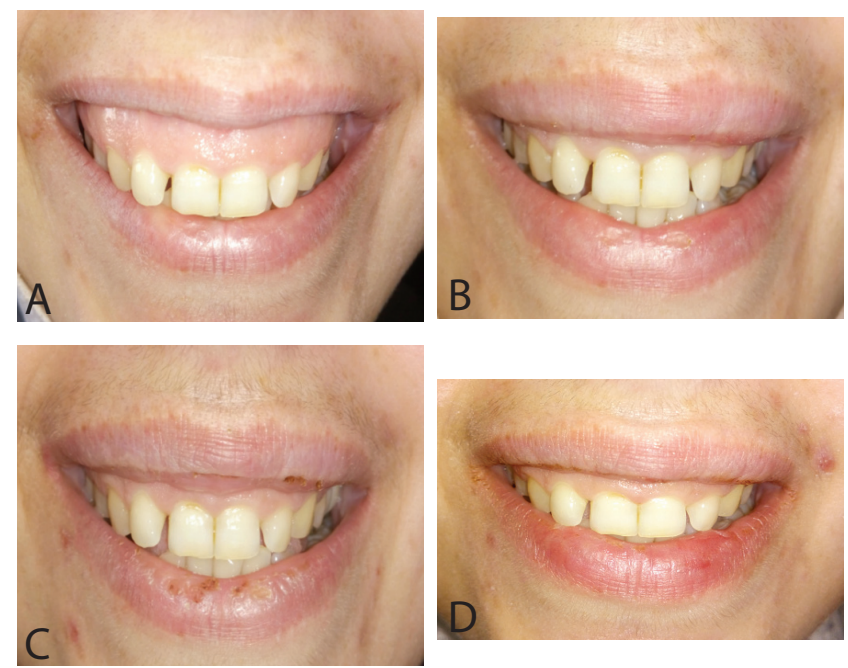

Fig. 4. Preoperative smile (A); smile at 1-month follow-up postoperatively (B); smile at 3-month follow-up postoperatively (C); smile at 6-month follow-up postoperatively (D)

\section{Statistical analysis}

Statistical analysis was conducted using the SPSS v. 13 (IBM Corp., Armonk, USA) and the data was analyzed using a descriptive analysis and the t-test, where $\mathrm{p}$-value $<0.05$ was considered significant.

\section{Results}

The most important complaint of most patients at the early stage of the postoperative follow-up period was tension feeling in the circumoral area and the upper lip. Specifically, 2 patients expressed blood oozing through the suture in the initial days following the surgery. Most patients expressed edema at a moderate rate, which disappeared in 7 days postoperatively, while only in 3 patients perioral area edema was extended to the lower eyelids with ecchymosis, which lasted for 14 days. Pain recurrences varied between mild pain in 5 patients (35.7\%) and moderate pain in 3 patients (21.4\%), which was controlled by means of analgesics. Flap dehiscence appeared in 2 patients (14.2\%) and numbness appeared in 9 patients $(64.2 \%)$. No infection was reported in any of the patients. Only 2 patients complained of dry mouth after surgery due to damage to the minor salivary glands in the upper lip mucosa during surgery. The mean rate of gingival display at baseline was $6.36 \mathrm{~mm}$ and changed significantly $(\mathrm{p}<0.05)$ at 1,3 and 6 months postoperatively. At 1,3 and 6 months, gingival display was $0.91 \mathrm{~mm}, 2.27 \mathrm{~mm}$ and $2.45 \mathrm{~mm}$, respectively (Table 1). There was a significant difference in gingival display between the results obtained after 1 and 6 months, but there was no significant difference in gingival display between the 3-and 6-month follow-up, so the results were fairly stable. At 1,3 and 6 months postoperatively, the obtained reduction was $5.45 \mathrm{~mm}, 4.09 \mathrm{~mm}$ and $3.91 \mathrm{~mm}$, respectively (Table 2, Fig. 5). The present study showed that no complete relapse was recorded in any case during the follow-up periods. However, a partial relapse was recorded in 6 patients.

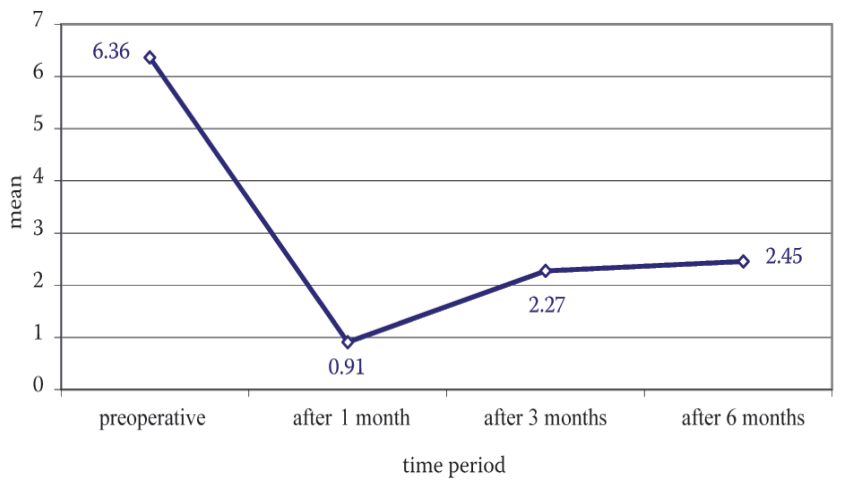

Fig. 5. The mean amount of gingival display in a full smile $[\mathrm{mm}]$ in relation to the time period 
Table 1. The mean, standard deviation, standard error, min, and max of the amount of gingival display in a full smile [mm] in the study sample

\begin{tabular}{|l|c|c|cc|c|c|}
\multicolumn{1}{|c|}{ Time period } & Number of patients & Mean & Standard deviation & Standard error & Min \\
\hline Preoperative & 14 & 6.36 & 1.12 & 0.34 & 0.37 & 0 \\
After 1 month & 14 & 0.91 & 1.22 & 0.38 & 0 \\
After 3 months & 14 & 2.27 & 1.27 & 0.34 & 4 \\
After 6 months & 14 & 2.45 & 1.13 & 4 \\
\hline
\end{tabular}

Table 2. Results of the interrelated-samples t-test to show significant differences in the mean values of gingival display in a full smile [mm] at 1,3 and 6 months postoperatively

\begin{tabular}{|l|c|c|c|}
\multicolumn{1}{|c}{ Periods compared } & Difference between the 2 means & t-test value & Degrees of freedom \\
\hline Preoperative - after 1 month & -5.45 & -11.066 & 10 \\
Preoperative - after 3 months & -4.09 & -8.964 & 0.000 \\
Preoperative - after 6 months & -3.91 & -10.618 & 0.000 \\
After 1 month - after 3 months & 1.36 & 4.404 & 10 \\
After 1 month - after 6 months & 1.55 & 4.949 & 10 \\
\hline
\end{tabular}

\section{Discussion}

Excessive gingival display or a "gummy smile" is considered undesirable by many people, which is why an attractive smile can improve the quality of life. The standard amount of gingival display varies between $1 \mathrm{~mm}$ and $3 \mathrm{~mm} .{ }^{16}$ When the amount of gingival display in a full smile is $\geq 4 \mathrm{~mm}$, the demand of most patients for an attractive smile is increased. In the literature, many treatment techniques have been reported for the management of a gummy smile, such as botulinum toxin injections, orthodontic surgery, crown lengthening, etc. ${ }^{1,4,12}$ In about $20 \%$ of patients, a gummy smile is caused by the hypermobility of the upper lip elevator muscles, so a myotomy of the lip elevator muscles can decrease a gummy smile by reducing the function of the muscles. ${ }^{4}$ Most patients prefer minor surgical techniques for the management of a gummy smile to major ones. The main goal of this study was to assess the outcomes of lip repositioning surgery (a full-thickness flap with a myotomy of the lip elevator muscles) in the treatment of a gummy smile, caused only by soft tissue disorders (short upper lip, hyperactive lip elevator muscles), to reduce the postoperative relapse in order to maintain stable surgical results for as long as possible and to assess the postoperative complications. All patients treated in this study had gingival display at the baseline ranging from 4 to $6 \mathrm{~mm}$. The technique presented in this article involved 2 full-thickness incisions connected together at the second upper premolar area, outlining an elliptical area of soft tissue which was removed; then, the attachments of the perioral muscles were dissected from the bone. This included the upper lip frenum area being $\mathrm{V}$-shaped to facilitate and maintain the position of the labial midline. The 2 incision lines were approximated by suturing the muscle layers; then, the mucosa layer was sutured with interrupted stabilization sutures. Accordingly, our results exhibited significant differences in the reduction of gingival display at 1, 3 and 6 months postoperatively. The mean postoperative gingival display at 1, 3 and 6 months postoperatively was $0.91 \mathrm{~mm}, 2.27 \mathrm{~mm}$ and $2.45 \mathrm{~mm}$, respectively. Successful rates at 1 and 6 months were $85.4 \%$ and $61.5 \%$, respectively. The results were stable for up to 6 months postoperatively. Only a partial relapse was noticed in 6 patients, without any complete relapse noted. This can be explained by incomplete stripping of the muscles from the bone during the surgical procedure or as a result of muscle memory reattachment to the previous pre-bone bases. These results are consistent with other studies concerning modified lip repositioning surgery. ${ }^{4,17}$ Our findings also correlate with a study conducted by Ellenbogen and Swara on 21 patients with a gummy smile, who were treated by a myotomy of the lip elevator muscles through the nose. ${ }^{15}$ In their study, silicone implants were used to prevent the relapse after surgery and they appeared to be effective in reducing gingival display. The most pronounced postoperative complication was the feeling of tension in the circumoral area and the upper lip as a result of removing during the operation a strip of the mucosa and muscles, and then suturing. That feeling disappeared within the first 2 weeks after surgery. Pain recurrences varied between mild pain in 5 patients (35.7\%) and moderate pain in 3 patients $(21.4 \%)$ during a few days postoperatively. The pain was controlled by analgesics. Flap dehiscence appeared in 2 patients $(14.2 \%)$ as a result of strong upper lip movement during the first 2 weeks after surgery. The patients with flap dehiscence were treated using disinfectant solution until the secondary healing was achieved. Numbness in the upper lip appeared in 9 patients $(64.2 \%)$, which gradually disappeared in the first month after surgery, after the patients were given a course of vitamin B-complex to enhance healing. No infection was reported in any of the patients as a result of infection control principles being followed during surgery and postoperatively. 
In the literature, there have been no studies on lip repositioning surgery by means of a myotomy of the lip elevator muscles for the management of a gummy smile and on its postoperative complications.

\section{Conclusions}

The surgical lip repositioning technique proposed in the current study is a less invasive procedure, carried out under local anesthesia, which has shown its effectiveness in reducing the amount of gingival display in a full smile through postoperative follow-up periods; therefore, it can be used to correct a gummy smile in patients with gingival display between 4 and $6 \mathrm{~mm}$. However, additional studies with longer follow-up periods and larger sample sizes may still be needed to evaluate the effectiveness of this technique.

\section{References}

1. Iqbal C, Nandakumar K, Padmakumar TP. Laser assisted treatment of excessive gingival display along with modified lip re-positioning. IOSR J Dent Med Sci. 2015;14(7):28-33.

2. Peck S, Peck L, Kataja M. The gingival smile line. Angle Orthod. 1992;62(2):91-100.

3. Levine RA, McGuire M. The diagnosis and treatment of the gummy smile. Compend Contin Educ Dent. 1997;18(8):757-762,764,quiz 766.

4. Abdullah W, Khalil $H$, Alhindi M, Marzook $H$. Modifying gummy smile: A minimally invasive approach. J Contemp Dent Pract. 2014;15(6):821-826.

5. Martins AT, Sakakura CE, Correcirc BE, et al. A modified technique that decreases the height of the upper lip in the treatment of gummy smile patients: A case series study. J Dent Oral Hyg. 2012;10:21-28.

6. Pandurić DG, Blašković $M$, Brozović J, Sušić M. Surgical treatment of excessive gingival display using lip repositioning technique and laser gingivectomy as an alternative to orthognathic surgery. J Oral Maxillofac Surg. 2014;72(2):404.e1-11.

7. Miron H, Calderon S, Allon D. Upper lip changes and gingival exposure on smiling: Vertical dimension analysis. Am J Orthod Dentofacial Orthop. 2012;141(1):87-93.

8. Hwang W-S, Hur M-S, Hu K-S, et al. Surface anatomy of the lip elevator muscles for the treatment of gummy smile using botulinum toxin. Angle Orthod. 2009;79(1):70-77.

9. Livada R, Shiloah J. Gummy smile: Could it be genetic? Hereditary gingival fibromatosis. J Tenn Dent Assoc. 2012;92(1):23-26.

10. Garber DA, Salama MA. The aesthetic smile: Diagnosis and treatment. Periodontol 2000. 1996;11:18-28.

11. Monaco A, Streni O, Marci MC, Marzo G, Gatto R, Giannoni M. Gummy smile: Clinical parameters useful for diagnosis and therapeutical approach. J Clin Pediatr Dent. 2005;29(1):19-25.

12. Simon Z, Rosenblatt A, Dorfman W. Eliminating a gummy smile with surgical lip repositioning. J Cosmet Dent. 2007;23(1):100-108.

13. Wei J, Herrler T, Xu H, Li Q, Dai C. Treatment of gummy smile: Nasal septum dysplasia as etiologic factor and therapeutic target. J Plast Reconstr Aesthet Surg. 2015;68(10):1338-1343.

14. Ishida LH, Ishida LC, Ishida J, Grynglas J, Alonso N, Ferreira MC. Myotomy of the levator labii superioris muscle and lip repositioning: A combined approach for the correction of gummy smile. Plast Reconstr Surg. 2010;126(3):1014-1019.

15. Ellenbogen R, Swara N. The improvement of the gummy smile using the implant spacer technique. Ann Plast Surg. 1984;12(1):16-24.

16. Silva CO, Ribeiro-Júnior NV, Campos TV, Rodrigues JG, Tatakis DN. Excessive gingival display: Treatment by a modified lip repositioning technique. J Clin Periodontol. 2013;40(3):260-265.

17. Benlier E, Top H, Aygit AC. A new approach to smiling deformity: Cutting of the superior part of the orbicularis oris. Aesthetic Plast Surg. 2005;29(5):373-377. 